\title{
A Girl with Joubert Syndrome: Association of Endocrinological Abnormality and New Radiological Findings
}

The Editor,

Sir,

An 8.6-year old girl was referred to the Endocrinology Outpatient Clinic due to the onset of puberty. There was consanguinity between parents who had no history of such disease. She had ventriculoperitoneal shunt due to congenital hydrocephaly. The patient was receiving sodium valproic acid since she had a seizure at two years of age. The patient had mentalmotor retardation with facial dysmorphism and ataxia, and tent-shaped gait. There was also facial asymmetry, arched eyebrows, nystagmus, ocular hypertelorism, broad forehead, as well as open and tent-shaped mouth [Figure 1]. According to Tanner staging, there was stage 3 breast development. At the presentation, body weight was $34 \mathrm{~kg}\left[68^{\text {th }}\right.$ percentile $]$ and height was $138 \mathrm{~cm}\left[59^{\text {th }}\right.$ percentile $]$. Her height-adjusted age and bone age were 9.96 and 10.5 years, respectively. Laboratory findings were as follows: free T4, $0.6 \mathrm{ng} / \mathrm{dL} ; \mathrm{TSH}, 1.1 \mathrm{mIU} / \mathrm{mL}$; FSH, $2.19 \mathrm{mIU} / \mathrm{L}$; LH, $6.43 \mathrm{mIU} / \mathrm{L}$; estradıol, $606 \mathrm{pg} / \mathrm{mL}$; ACTH, $30 \mathrm{pg} / \mathrm{mL}$; cortisol, 12 $\mathrm{mcg} / \mathrm{dL}$. There was precocious puberty and hormone profile consistent with central hypothyroidism, while kidney and liver function tests were normal. On magnetic resonance imaging (MRI), bilateral kidneys were localized at lower abdominal quadrant, while multicystic hypertrophic ovaries were observed at bilateral iliac anterior pararenal areas, and no uterus was seen. On cranial MR imaging, occipital horn of right lateral ventricle was asymmetrically dilated and there was brainstem atrophy [Figure 2a], and asymmetrical dilatation in occipital horn of right lateral ventricle-atrium [Figure 2b]. İt was seen that there was a molar tooth sign [Figure 3a], hypoplasia in cerebellar vermis, and bat wing appearance 
on fourth ventricle [Figure 3b]. In addition, corpus callosum posterior splenium was thinner [Figure 4a]; there was macroadenoma in the pituitary gland [Figure 4b].

In almost all cases with Joubert Syndrome (JS), there is a molar tooth sign, varying degrees of developmental delay/mental retardation, and history of hypotonia during infantile period. Supportive findings include nystagmus, abnormal ocular movements, and irregular respiration at infantile period. In addition, some authors propose that dysmorphic facial characteristics can be considered within diagnostic criteria $(5,8)$.

In this case, supportive findings for JS were history of shunt due to congenital hydrocephaly at childhood, hypotonicity, walking delayed until three years of age, inability to speak and nystagmus. Although hydrocephaly has been reported, up to $10 \%$, development of hydrocephaly requiring shunt is extremely rare $(9,10)$. However, there was shunt in our case. The most common ocular finding is oculomotor apraxia. There was also nystagmus and exophthalmia in our case. Hypothyroidism was previously reported in JS (1). In this case, JS was associated with pituitary macroadenoma, ectopic kidneys and ovaries, precocious puberty, hypothyroidism and uterine agenesis. The findings other (SOMETHING SEEMS MISSING)hypothyroidism has never been reported in association with JS. We presented this case to emphasize that screening patients with JS could help early diagnosis; thus, improve clinical outcomes.

Keywords: Ectopic ovaries and kidneys, Joubert syndrome, puberty, uterine agenesis

S Kaba, M Doğan, MD Bulut, N Demir, K Bulan, S Kocaman

From: Department of Paediatrics, Division of Paediatric Endocrinology, YYU School of Medicine, Van, Turkey. 
Correspondence: Sultan Kaba, MD, Yuzuncu Yil University, School of Medicine, Department of Paediatrics, Division of Paediatric Endocrinology, Van, 65100, Turkey. Fax: +90432 2155281,e-mail: sultan33kaba@hotmail.com 


\section{REFERENCES}

1. Parisi MA, Doherty D, Chance PF, Glass IA. Joubert syndrome (and related disorders) (OMIM 213300). Eur J Hum Genet 2007; 15: 511-21.

2. Zamponi N, Rossi B, Messori A, Polonara G, Regnicolo L, Cardinali C. Joubert syndrome with associated corpus callosum agenesis. Eur J Paediatr Neurol 2002; 6: $63-6$.

3. Ishikawa T, Zhu BL, Li DR, Zhao D, Michiue T, Maeda H. An autopsy case of an infant with Joubert syndrome who died unexpectedly and a review of the literature. Forensic Sci Int 2008; 179: e67-73.

4. Joubert Syndrome Foundation. 2003. [Accessed February 19, 2003]. Available athttp://www.joubertsyndrome.org.

5. Parisi MA, Doherty D, Chance PF, Glass IA. Joubert syndrome and related disorders. European Journal of Human Genetics 2007; 15: 511-521.

6. Gleeson JG, Keeler LC, Parisi MA (WHO ARE THE OTHER AUTHORS?)et al. Molar tooth sign of the midbrain-hindbrain junction: occurrence in multiple, distinct syndromes. Am J Med Genet 2004; 125A: 125- 134; discussion 117.

7. Valente EM, Salpietro DC, Brancati F (WHO ARE THE OTHER AUTHORS?)et al. Description, nomenclature, and mapping of a novel cerebello-renal syndrome with the molar tooth malformation. Am J Hum Genet 2003; 73: 663- 670.

8. Maria BL, Quisling RG, Rosainz LC (WHO ARE THE OTHER AUTHORS?)et al: Molar tooth sign in Joubert syndrome: clinical, radiologic, and pathologic significance. J Child Neurol 1999; 14: 368- 376.

9. Maria BL, Bozorgmanesh A, Kimmel KN, Theriaque D, Quisling RG. Quantitative assessment of brainstem development in Joubert syndrome and Dandy-Walker syndrome. J Child Neurol 2001; 16: 751-758. 
10. Genel F, Atlihan F, Ozdemir D, Targan S. Development of hydrocephalus in a patient with Joubert syndrome. J Postgrad Med 2004; 50: 153.

11. Graber JJ, Lau H, Sathe S. Teaching neuro images: molar tooth sign with hypotonia, ataxia, and nystagmus (Joubert syndrome) and hypothyroidism. Neurology 2009; 15: 73; e106. 


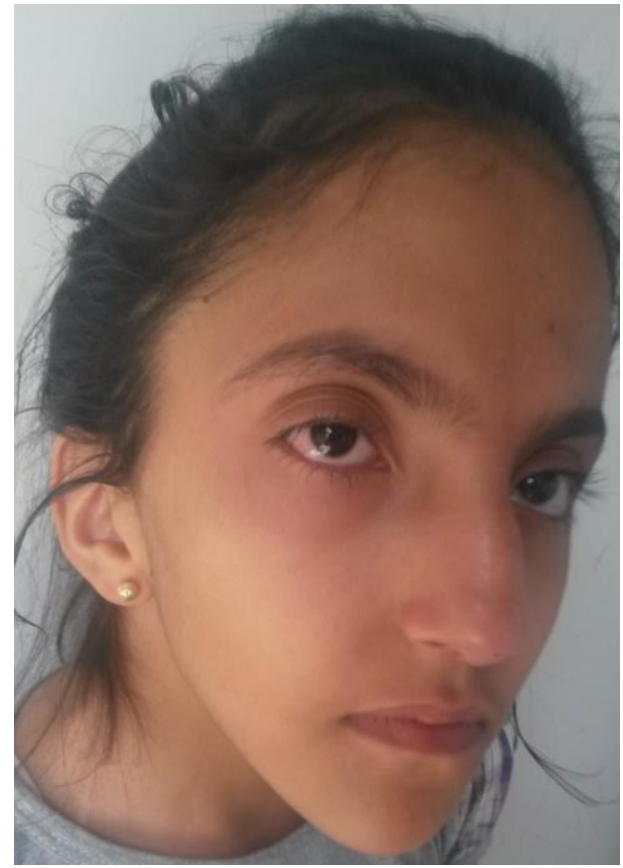

Figure 1: Facial asymmetry, arched eyebrow, nystagmus, ocular hypertelorism, broad forehead.

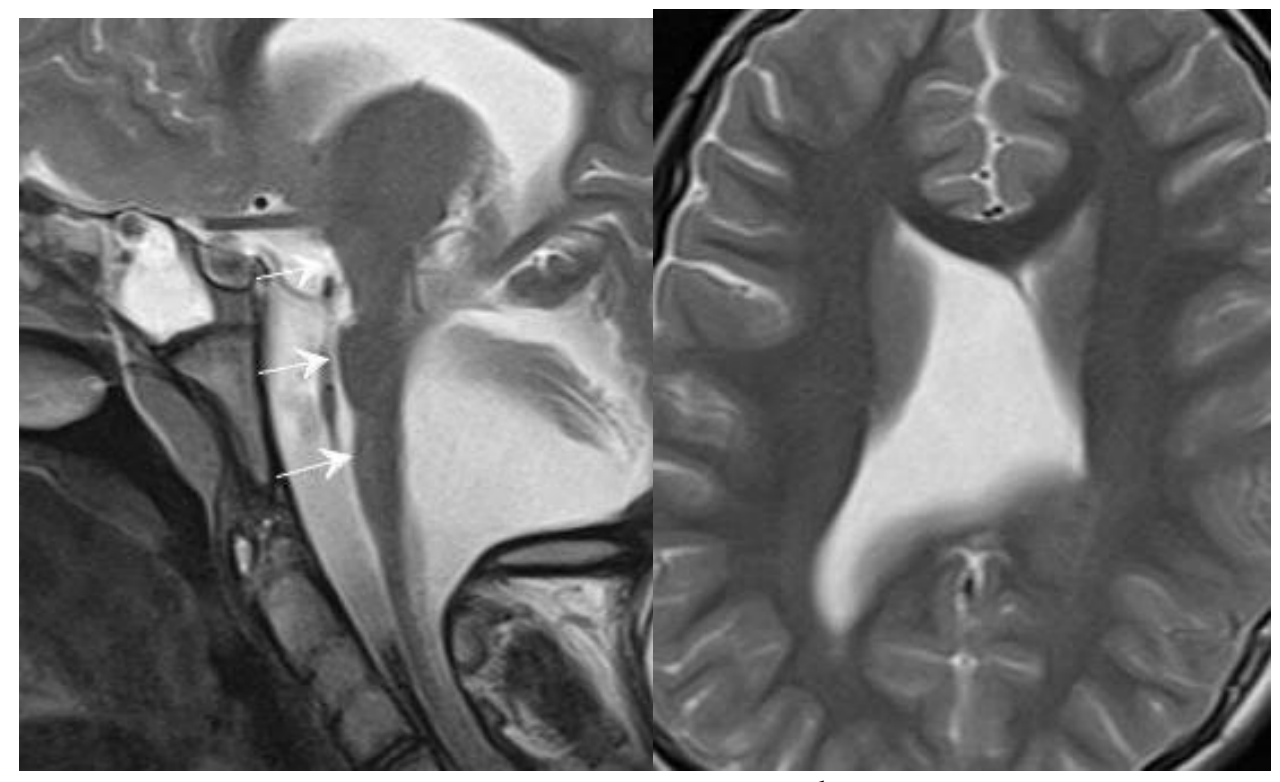

a

b

Figure 2: T2-weighted sagittal image; (a) brainstem atrophy on axial image; (b) asymmetrical dilatation in occipital horn of right lateral ventricle-atrium. 


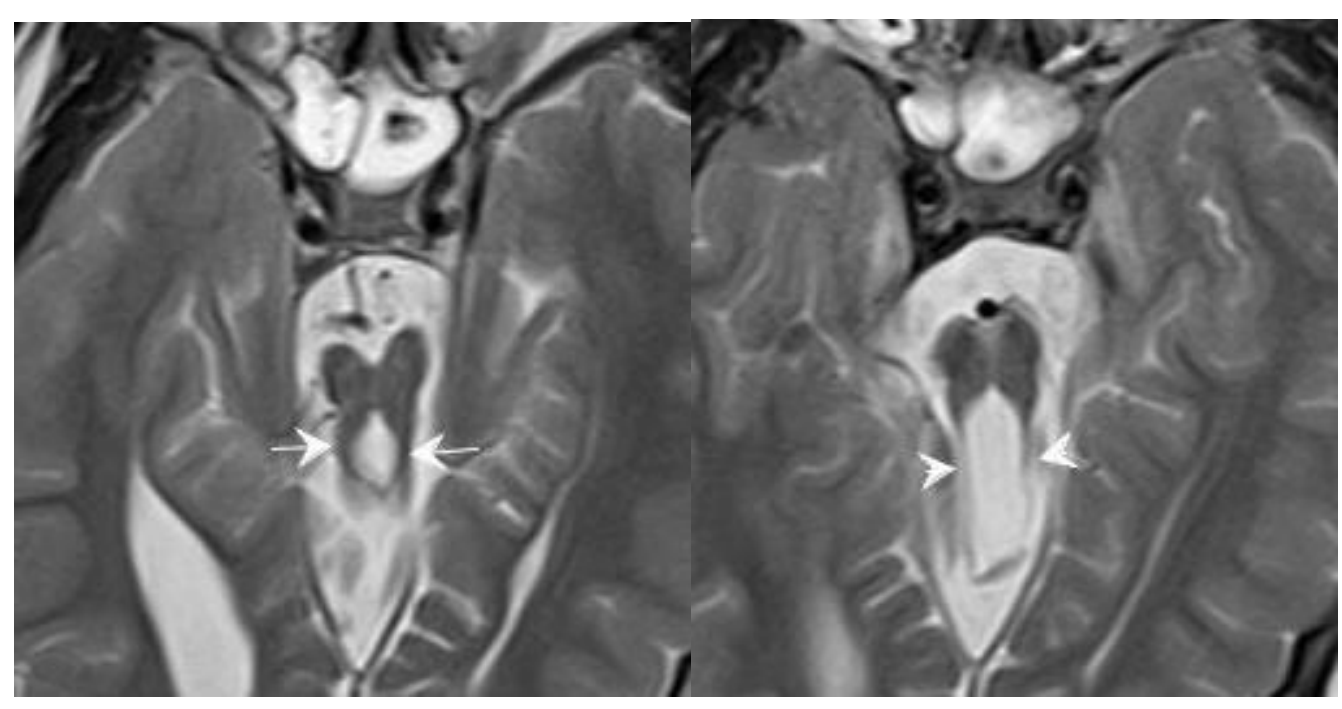

a

b

Figure 3: T2-weighted axial image; $(\mathrm{a}, \mathrm{b})$ molar tooth appearance at superior cerebellar pedicles and bat wing appearance at fourth ventricle (arrow).

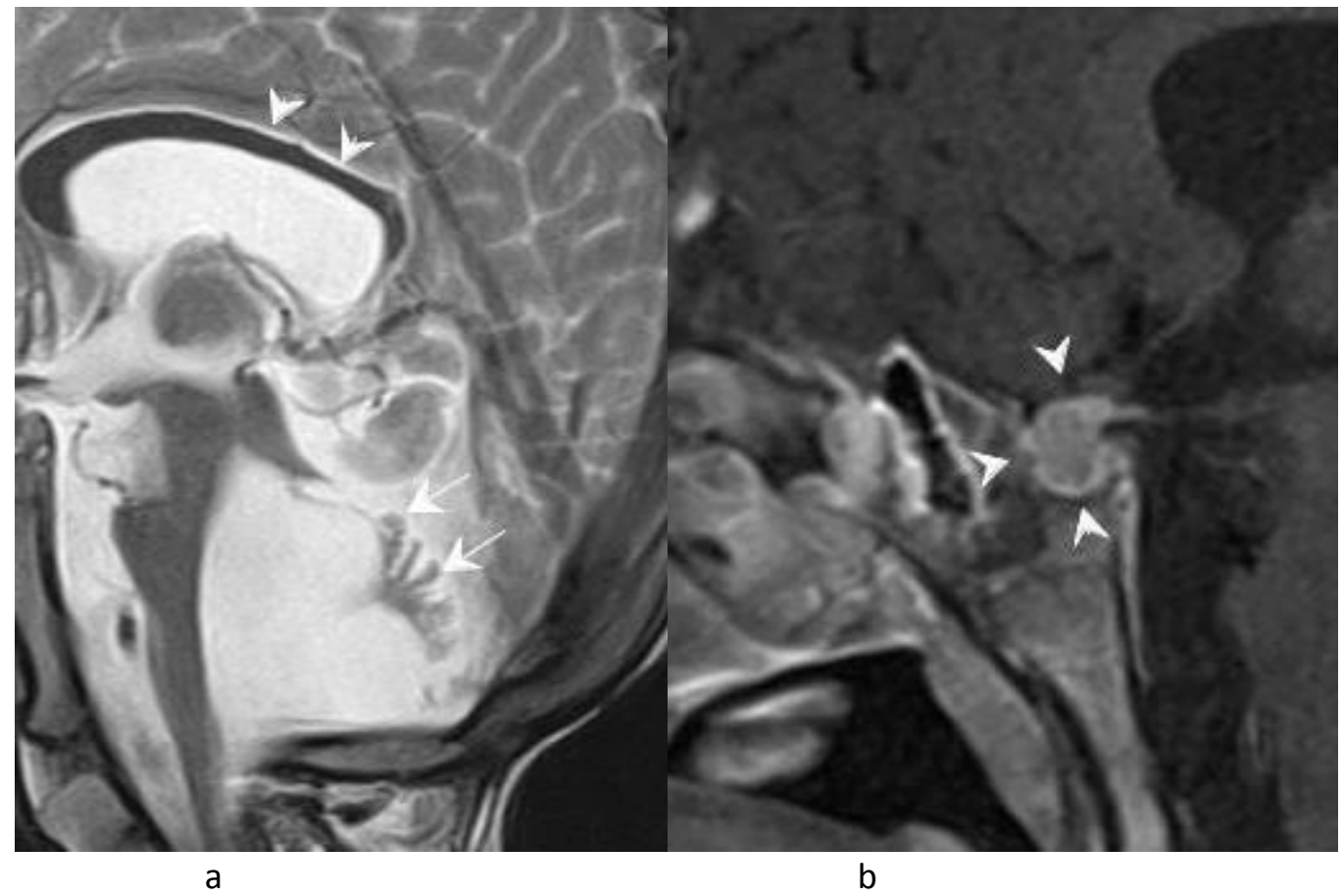

Figure 4: T2-weighted sagittal image; (a) dysgenetic appearance of corpus callosum, posterior splenium is thinner than normal (b) macroadenoma at pituitary gland. 